\title{
UN GRAVE CONFLICTO \\ EN LAS UNIVERSIDADES DEL SIGLO XIII: LOS FRAILES EN LOS «STUDIA»
}

Salvador Claramunt

Universitat de Barcelona

«Si quitamos de la vida los pocos instantes de religión, de arte y de amor puro, ¿qué queda sino una serie de pensamientos triviales?». Esta frase de Schopenhauer sirve para recordar con todo cariño a Regina, y a la vez como introducción de uno de los problemas más graves que tuvo la entonces naciente institución universitaria y que, en realidad, no fue más que una situación trivial, dramatizada por la subsistencia cotidiana en el marco de la lucha por el control de los «Studia»; si bien todo ello quedó inmerso en un enfrentamiento filosófico de envergadura.

En la segunda mitad del s. XIII muchos «Studia» del occidente de Europa, se vieron envueltos en una violenta disputa académica conocida con el nombre de controversia escolástica. El centro del conflicto era París, aunque la controversia se extendió también a otras universidades, como las de Toulouse, Montpellier y Orleans. Al parecer, la cuestión que desencadenó los debates fue el derecho de los «Studia» (universidades) -claramente expresado en el documento de París de 1255- a estudiar las nuevas obras de Aristóteles recién descubiertas y, según algunos, heréticas, especialmente los tratados de metafísica y filosofía natural. La controversia se llamó escolástica por haberse desarrollado en las escuelas y tener por protagonistas hombres de escuela, pero de ningún modo puede creerse que se trató de una mera disputa intrascendente entre mentes frívolas; muy al contrario constituyó el acontecimiento intelectual más importantes del siglo XIII. 
Los problemas que se ventilaban eran de considerable transcendencia: aceptar sin más la filosofía natural de Aristóteles equivalía a poner en tela de juicio toda la base metafísica de las doctrinas agustinianas, sostenidas tradicionalmente por la Iglesia, con la consiguiente merma de autoridad religiosa de ésta. Además se abría así el camino a una explicación totalmente naturalista y racional del universo, lo que era un evidente peligro para la misma Iglesia.

En cualquier caso, el papado necesitaba reforzar sus vínculos con la Universidad de París y con Francia misma.

El reino de Francia durante los turbulentos siglos XI y XII, merced a la estabilidad que le proporcionó la dinastía capeta, había sido un pilar de fuerza y de estabilidad para el pontífice romano. A principios del s. XIII Roma, por su parte, iba perdiendo apoyo e influencia en la península italiana. Federico II dominaba sobre el reino de Sicilia y para mejor hacer valer su independencia fundó una universidad en Nápoles, a la que otorgó el derecho de conferir el ius ubique docendi por real privilegio de $1224^{\prime}$. Asimismo, en el norte de la península itálica, la liga lombarda de ciudades independientes iba ganando poder y se mostraba cada vez más indiferente al poder temporal de la Iglesia.

Era, pues, imperativo para esta última entenderse con las universidades, especialmente con la de París; ya que no sólo las universidades se habían convertido en las más importantes instituciones de vida intelectual, sino que ejercían también una autoridad moral considerable, y su fuerza corporativa era tal que en ocasiones llegaban a influir en la política real. El papado, que gozaba ya de bastante buenas relaciones con París, trató a comienzos del s. XIII de estrechar aún más sus vínculos con esta universidad y granjearse así un poderoso aliado. Pero reforzar estos lazos no era tarea fácil; París comenzaba ya a dar muestras de un espíritu de independencia y a apreciar la nueva fuerza que era capaz de ejercer una corporación de intelectuales. Además, tampoco constituía una voz unánime en lo tocante a las opiniones académicas.

En esta época en que se iniciaron dichos acontecimientos, la Iglesia no carecía de influencia en París. La universidad se hallaba nominalmente sujeta al obispo de París y, por consiguiente, al papa, pero a comienzos del

\footnotetext{
'Véase S. ClaRamunt, L'organització de l'Estat i la política universitària de Frederic II, "L’Avenç", 195 (Barcelona, set. 1995), pp. 22-28.
} 
s. XIII Roma no estaba demasiado ansiosa de poner a prueba dicha dependencia de modo serio. De hecho, la Iglesia influía directamente en la universidad por medio de los maestros de la facultad de teología, que ya muy a principios del s. XIII se habían erigido a sí mismo en paladines de la ortodoxia, dando nacimiento en el proceso a un marcado antagonismo hacia el clero secular de otras facultades ${ }^{2}$. En realidad, esta enemistad iba enteramente dirigida a la facultad de artes. Aunque al principio en la facultad de teología enseñaban maestros seculares, en el tiempo de la gran dispersión de 1229-31 sus miembros se reclutaban ya casi en su totalidad entre los miembros de dos nuevas órdenes religiosas, cuya actividad se hallaba al servicio de una concepción militante de la ortodoxia.

Estas dos nuevas órdenes tuvieron su origen durante el turbulento período de las herejías valdense y albigense, en los primeros años del s. XIII. Dichas herejías no dejaron de tener sus consecuencias, y su aparición motivó una ola de entusiasmo por la reforma eclesiástica. Conocidas popularmente como «los franciscanos» $\mathrm{y}$ «los dominicos», nombre procedente de sus respectivos fundadores, ambas órdenes se convirtieron por su devoción a los ideales de austeridad y pobreza en herederas de las primitivas reformas monásticas de Cluny y del Cister, de 910 y 1098 respectivamente, las cuales estaban ya en franca decadencia, especialmente como guías espirituales, no tanto como potencias económicas.

Aunque las dos órdenes respondían a situaciones muy concretas - los dominicos en particular nacieron para enfrentarse específicamente con el problema cátaro ${ }^{3}$-, pronto ampliaron el campo de sus actividades hasta llegar a ejercer un profundo influjo en la direccción de los asuntos de la Iglesia. En especial se interesaron por los aspectos educativos y, en el transcurso del s. XIII, acabaron por dominar la Universidad de París, así como otras universidades del norte, incurriendo en la constante hostilidad de los maestros seculares. Ambas órdenes tomaron parte activa en la controversia escolástica, y los dominicos, que hicieron de ella asunto propio, ocuparon el centro de los debates.

\footnotetext{
2Sobre este crucial período para la evolución de la autonomia universitária véase: Azucena A. FrabosChi, Crónica de la Universidad de París y de una huelga y sus motivos (1200-1231), Instituto de Estudios Grecolatinos "Prof. F. Novoa", Buenos Aires, 1991.

${ }^{3}$ Para la historia de la primera época de los dominicos, véase W.A. HinnebusCh, The History of Dominican Order, I, Nueva York, 1965.
} 
Según la regla franciscana de $1223^{4}$ el logro de la salvación personal era el foco principal de su interés, los frailes menores ponían especial énfasis en las prácticas ascéticas, sin preocuparse mayormente por el trabajo en sí mismo. Según este principio, la regla incluso disociaba a los frailes menores de la dirección de escuelas o de cualquier otra actividad intelectual; el artículo diez expresamente ordenaba que los frailes «no trataran ni siquiera de dar instrucción a los ignorantes, sino que en lugar de ello dirigieran sus esfuerzos a poseer el espíritu de Dios». Las necesidades de los tiempos, sin embargo, eran otras; claramente no podían ignorarse los asuntos relativos al mundo de las letras, ni el ritmo cada vez más acelerado de la vida intelectual. La orden acabó, pues, por dividirse en dos grupos, uno radical que pretendía seguir la regla al pie de la letra y cuyos miembros se denominaron «espirituales», y otro, más moderado de, "conventuales», que reconocían la necesidad del estudio y demás actividades intelectuales. A medida que fueron erigiéndose nuevas casas, los conventuales fundaron escuelas donde podían llevarse a cabo estudios completos de artes liberales, como en las universidades de entonces. Esta característica de la vida conventual franciscana siguió manteniéndose, y de sus escuelas salieron después, en el s. XIII, algunas de las más importantes figuras intelectuales de la época, en particular Juan de Fidanza (1221-1274), que llegó a ser general de la orden con el nombre de Buenaventura y Roger Bacon (1210/14-1294), uno de los más discutidos y sin duda alguna el más incómodo de los miembros que la orden jamás tuviera.

Por su parte los dominicos abrazaron el ideal de pobreza ${ }^{5}$, si bien la humildad nunca fue uno de sus rasgos más destacados. Al contrario, la orden de Predicadores se desarrolló rápidamente como organización especializada en las técnicas de la elocuencia y persuasión, manifestando una marcada predilección por los debates teológicos e intelectuales de todo tipo, de tal modo que en el s. XIII llegó a convertirse en el ala militante de la Iglesia desde el punto de vista intelectual.

Los dominicos, como hemos visto antes los franciscanos, fundaron sus propias escuelas que enseñaban el programa de las artes liberales como

\footnotetext{
${ }^{4}$ Véase John Moorman, A History of the franciscan order. From its origins to the year 1517, Orford Press, 1968.

${ }^{5}$ Sobre el ideal de pobreza de franciscanos y dominicos, véase la Parte III, de la obra de Lester K. LiTTLE, Pobreza voluntaria y economía de beneficio en la Europa medieval, titulada "El confrontamiento de la crisis: canónigos, laicos y frailes". Madrid, ed. Taurus, 1983.
} 
se estilaba entonces. En el transcurso del s. XIII algunas de estas escuelas llegaron a ser tenidas en alta estima por la calidad académica de su instrucción, en particular la de Colonia, que se hizo célebre bajo la dirección del eminente teólogo Alberto Magno (1206-1280). No obstante, estas escuelas dominicanas se distinguían por el carácter totalmente interno de su enseñanza y por sus actitudes conservadoras de cara al exterior. Ninguna de ellas hizo progresar ideológicamente la educación: la evolución intelectual se centraba más bien en las nacientes universidades. Precisamente será en estas instituciones donde los dominicos conseguirán hacer valer su influjo intelectual, siendo el ejemplo más notable la manifestación del genio del más ilustre de sus miembros, Tomás de Aquino.

Los primeros dominicos llegaron a París en 1217, y los franciscanos unos dos años más tarde. A lo largo del mismo siglo, las dos órdenes acabaron controlando del todo las vida de las dos facultades de artes y teología respectivamente. A ellos se debió, entre los años 1250 y 1280, el brote de la controversia escolástica en gran escala de dos importantes doctrinas rivales: el neoplatonismo agustiniano y el aristotelismo cristiano.

Una pregunta que debemos hacernos es: ¿por qué los dominicos que tenían su organización escolar propia, van a la busca del control teológico de la institución universitaria? La explicación se debe buscar en los mismos orígenes de la Orden, Santo Domingo había constituido su primera comunidad en el Languedoc ${ }^{6}$, región carente de una escuela de teología. Por eso, él mismo dispersó esta comunidad en 1217, enviando a sus frailes hacia las grandes ciudades universitarias de la época, París y Bolonia. Con ello se proponía dos objetivos, que fueron totalmente alcanzados: permitir a sus primeros frailes recibir una formación teológica que les faltaba, y reclutar nuevos miembros en los medios universitarios.

Los seguidores de Domingo de Guzmán fueron bien acogidos en las universidades; estaban especialmente recomendados por el papa y su estilo de piedad seducía a numerosos universitarios. En París, un maestro en teología, Juan de Barastre les ofreció una casa cerca de la puerta de SaintJacques y él mismo fue a enseñar allí.

En los años sucesivos la entrada en la orden de maestros y bachilleres conocidos, como Jourdain de Sajonia, Jean de Saint-Gilles en

\footnotetext{
${ }^{6}$ Sobre el importante papel de la orden de los predicadores en el sur de Francia, véasen los diferentes trabajos editados en el volumen de Cahiers de Fanjeaux, Les universités du Languedoc ciu XIII' siècle, Toulouse, Privat, 1970.
} 
París, Moneta de Cremona en Bolonia, que continúan enseñando en sus cátedras con su nuevo hábito, acabó ligando los conventos dominicos a las universidades.

El proceso fue muy parecido entre los franciscanos, a pesar de que san Francisco ${ }^{7}$ a su regreso de Tierra Santa en 1220 hizo cerrar la casa en donde ciertos frailes, instalados en Bolonia, daban conferencias espirituales que parecían mucho enseñanzas de teología, entre ellos se encontraba Antonio de Lisboa, más conocido después como de Padua. Pero a la muerte del fundador, la orden franciscana se introdujo en las universidades. El modelo lo habían dado los dominicos, la buena acogida de los estudiantes y de los profesores facilitó la posterior evolución favorable. Algunos afamados maestros, como Aimon de Faversham o Alejandro de Hales, tomaron el hábito franciscano y dieron a la orden sus primeros teólogos.

Esta buena acogida y entendimiento inicial deben hacernos recordar que los mendicantes en realidad no estaban verdaderamente integrados en la universidad: ellos suponían un verdadero peligro permanente al no respetar la solidaridad interna de la propia institución, que había sido la base en torno a la cual se había desarrollado la corporación universitaria.

En el interior de la facultad de teología, los mendicantes continuaban dependiendo estrictamente de su orden. En las universidades, como las de Toulouse, Montpellier o Bolonia, donde no había facultades de teología, no había demasiados problemas, ya que los conventos de mendicantes hacían el papel de facultad de teología; los doctores iban a buscar su título a París o lo recibían directamente del papa.

Pero en París y en Oxford, donde ya había facultades de teología llevadas por profesores seculares, la situación rápidamente se hizo tensa. Los maestros mendicantes no actuaban más que en función de los intereses de su orden, sin tener en cuenta los problemas propios de la corporación universitaria; no se sentían concernidos por las preocupaciones de sus colegas seculares, como la autonomía en la relaciones con el obispo, el problema siempre vital de las remuneraciones, etc.; tampoco solicitaban los honorarios, y atraían a los estudiantes que abandonaban las otras escuelas;

\footnotetext{
${ }^{7}$ Una nueva visión sobre la personalidad de Francisco de Asís la da la muy recién aparecida obra de Jacques Dalarun, François d'Assise et la question du pouvoir, Bruxelles, Ed. De Boeck, 1999. En que se nos presenta una nueva faceta, de lo que hoy se llamaría en la jerga planificadora misión-visión, de san Francisco.
} 
no obedecían más que las órdenes de sus superiores y no hacían caso de las decisiones de la universidad. En resumen, sin contribuir para nada a la defensa de la corporación universitaria, amenazaban con privar a los maestros seculares de sus cátedras y de sus alumnos, o sea de su modus vivendi.

Ya, cuando la gran dispersión de 1229-1231, los mendicantes no habían seguido al resto de la corporación universitaria. Todo lo contrario, habían aprovechado la ausencia de los maestros seculares para hacerse otorgar directamente por el canciller la licencia en teología a uno de ellos, Rolando de Cremona, que fue el primer maestro en teología dominico. A su regreso, los seculares no magnificaron el incidente, pero no lo olvidaron, ya que veinte años más tarde, la crisis estalló, por razones análogas, y esta vez de modo violentísimo.

El papa había autorizado al canciller a dar la licencia en teología a todo religioso mendicante que fuese digno de ello (1250), hecho que suponía el derecho de presentación y prácticamente de cooptación de los profesores. A ello se añadió que en 1253 los mendicantes habían rehusado, una vez más, adherirse a una huelga. La universidad respondió limitando a una por convento las cátedras de los regulares (mendicantes y regulares tradicionales), y exigiendo de todos sus miembros un juramento de obediencia al conjunto de los estatutos de la universidad. Habiendo rehusado, los regentes de cátedra mendicantes fueron excluidos, a la vez que el papa suspendía los privilegios de la universidad. El conflicto estaba abierto y el debate fue llevado ante la opinión pública.

En una carta a los obispos de 1254 , los maestros seculares expusieron sus agravios y, en medio de una gran cantidad de cifras, algunas veces trucadas y en otros casos totalmente hipotéticas, intentaron mostrar que la proliferación de los maestros regulares amenazaba con privarles de estudiantes y de sus propios medios de subsistencia. A todo ello añadían que la actitud de los mendicantes en cuanto a su rechazo de jurar los estatutos universitarios mostraba bien a las claras que el único interés de éstos era aprovecharse de las ventajas de la universidad, a la vez que se escapaban de las obligaciones del sistema corporativo.

La carta revela la gravedad del conflicto; ya que se trataba del enfrentamiento de dos concepciones diversas de universidad, dos mentalidades que se enfrentaban; al celo apostólico, a veces brutal, de los mendicantes, se oponían las concepciones maltusianas de los maestros seculares que, 
como en toda corporación, querían limitar la producción y los efectivos de la profesión para mejor asegurarse su monopolio.

La muerte de Inocencio IV en 1254 impidó todo compromiso, ya que su sucesor Alejandro IV, en la bula Quasi lignum vitae, se puso claramente a favor de los mendicantes.

El nuevo pontífice decidió qué maestros debían ser reintegrados en sus funciones universitarias y eliminó la limitación en el número de cátedras; a la vez que intentó desarmar a los seculares restringiendo el derecho de huelga , ya que para ejercerlo sería desde entonces necesario contar con una mayoría de dos tercios, mayoría que en la facultad de teología, no podía alcanzarse sin el apoyo de los mendicantes. Los maestros seculares no aceptaron esta solución y Alejandro IV los excomulgó en bloque, a lo que ellos respondieron disolviendo oficialmente la universidad y organizando un boicot de los cursos de los mendicantes. El conflicto había alcanzado el paroxismo.

En este durísimo enfrentamiento los mendicantes contaron con el apoyo del papa y del rey Luis IX. Pero los maestros seculares, entre los que destacaba la figura de Guillermo de Saint-Amour, estaban decididos a todo y podían contar con la simpatía de buena parte de la opinión pública y del clero, especialmente del episcopado que toleraba mal la intromisión de los mendicantes en todos los aspectos de la vida pastoral de las diócesis. De esta manera, sobrepasando el nivel de los agravios corporativos, Guillermo de Saint-Amour y sus amigos situaron el debate en un plano más elevado, dedicándose a una crítica sistemática de las órdenes nuevas, mostrando que estas órdenes no debían de tener un lugar en la universidad, ni en la propia Iglesia. En este empeño un paso falso de los franciscanos les facilitó la labor; éste consistió en la publicación que hizo el franciscano Gerardo de Borgo San Donnino, de la Introducción al evangelio eterno (de Joaquín de Fiore), que presentaba a san Francisco como un nuevo Cristo y a su orden como destinada a instaurar «la Iglesia de los últimos tiempos», la de Espíritu Santo, fundada sobre la pobreza, en lugar de la Iglesia existente. Inmediatamente, y a pesar de que Gerardo de Borgo San Donnino fue condenado por su orden, los seculares acusaron a los mendicantes de herejía, de hipocresía, indiscreción, etc..., para finalmente denunciar la pobreza y la mendicidad

\footnotetext{
${ }^{8}$ Sobre este conflicto, véase el capítulo 13: La Facultad de Teología, de Monika AszTaLoS, en el vol. I, Historia de la Universidad europea, ed. Hilde de RIDEER-SYMOENS, Bilbao, 1994.
} 
como unos falsos ideales. Todas las crítcas posibles fueron reunidas por Guillermo de Saint-Amour en un vigoroso panfleto titulado «Sobre los peligros de los tiempos nuevos» de 1256.

A pesar de todo, la última palabra la tuvieron los mendicantes. Ya que san Buenaventura y santo Tomás de Aquino supieron replicar a los seculares defendiendo, el primero el ideal de pobreza; el segundo, el derecho de las nuevas órdenes a dedicarse a la enseñanza y a la predicación y no al trabajo manual, como los antiguos monjes; a la vez que el papa Alejandro IV rompió la resistencia de los maestros seculares, llamando a Roma a los más importantes, que acabaron por someterse, mientras que el irreductible Guillermo Saint-Amour fue condenado, excluido de la universidad y expulsado de Francia por orden de Luis IX.

En 1261 el nuevo papa, Urbano IV reintegró solemnemente a los mendicantes en la universidad; los dominicos tuvieron el derecho a tener dos cátedras de teología, las otras órdenes una; a la vez que todas las sentencias llevadas a cabo contra los seculares, excepto contra Guillermo Saint-Amour fueron retiradas y, el conjunto de los privilegios universitarios confirmados.

Esta gran crisis universitaria, centrada entre 1252 y 1261 , no fue más que un episodio de otra más que duraría hasta principios del s. XIV, y que enfrentó en toda la Iglesia occidental a los clérigos seculares y a los religiosos mendicantes. La universidad de Oxford la conoció entre 1303 y 1320. En realidad, el meollo de este debate sobrepasaba los problemas universitarios, ya que estaba en el mismo conjunto de las concepciones eclesiológicas (centralización pontificia) y morales (pobreza y mendicidad) de los mendicantes.

La universidad continuó participando en este debate; de 1282 a 1290, los maestros seculares de París sostuvieron a los obispos franceses en su resistencia a la bula Ad fructus uberes, que permitía a los mendicantes predicar y confesar sin autorización del clero local. Pero, esta vez, estas actitudes no supusieron un nuevo estallido en el seno de la universidad, en donde continúo en vigor el compromiso impuesto por Urbano IV.

La política del papado, y muy especialmente la de Alejandro IV, fue la de poner a su servicio a la universidad, más que favorecer su desarrollo, y nada mejor para ello que favorecer la introducción de sus partidarios más seguros y combativos, los religiosos mendicantes. Baste como punto de referencia lo que el legado pontificio Benedicto Gaetani - el futuro Bonifacio VIII- dijo a los maestros parisienses: «La corte de Roma, antes que revocar el privilegio de los frailes mendicantes, romperá la universidad de París. Ya 
que no hemos sido llamados por Dios para adquirir ciencia o brillar ante las miradas de los hombres, sino para salvar nuestras almas».

Todo este enfrentamiento entre seculares y mendicantes (1252-1261), patético desde el punto de vista institucional, redundó beneficiosamente desde el punto de vista intelectual para la universidad de París. De hecho la victoria de los mendicantes fue mucho más beneficiosa para la universidad de París que si la balanza se hubiese decantado por los seculares, ya que figuras como las de san Buenaventura o santo Tomás nunca hubiesen regentado cátedra en la universidad.

La victoria definitiva de los mendicantes en la universidad, supuso la afirmación y esplendor de las diferentes escuelas, de las que citamos solamente, por ser las más importantes las siguientes:

En la universidad de Oxford, las matemáticas y ciencias naturales tuvieron como genio indiscutible la figura de Roger Bacon (1210-1291), discípulo de Grosseteste, que continúa su herencia intelectual. Bacon rompe los moldes en uso y no escatima la crítica del ambiente en que se mueve. No respeta ni a personajes constituidos en altos puestos de prestigio. A Alejandro de Hales y a Alberto Magno los tilda de ignorantes.

Estuvo recluido en la prisión de su convento franciscano desde 1271 hasta poco antes de su muerte en 1291.

Por otro lado, la antigua escuela franciscana, encarnada por los hombres del agustinismo, se manifiesta en la tradicional corriente agustiniana. No quiere decir esto que sólo los franciscanos hagan honor a la tradición y al pensamiento agustiniano; esto también lo hicieron Alberto Magno y Tomás de Aquino, la primera escuela dominicana y los maestros del clero secular. Pero la verdad es que los franciscanos son los seguidores declarados de san Agustín y que suscriben del modo más tenaz y duradero una serie de tesis características de aquél, que les discriminan netamente de los dominicos y de su aristotelismo.

La antigua escuela franciscana se abre con Alejandro de Hales (11701245), y la continúa de inmediato su discípulo Juan de Rupella, su sucesor en la cátedra de París (1200-1245).

El más grande representante de este grupo es san Buenaventura (1221-1274), figura señera de la Alta Escolástica junto con santo Tomás. Fue profesor en París al mismo tiempo que santo Tomás y luchó a su lado en la contienda en torno a los derechos de las órdenes mendicantes a las cátedras de la universidad. Desde 1257 se consagra exclusivamente a las tareas de su 
Orden y de la Iglesia; en 1279 es nombrado cardenal y dirige el concilio de Lyon. Recibirá el título de «Doctor Seraphycus»

Entre los dominicos, san Alberto Magno ocupa el primer plano intelectual, y con él también llega a su punto culminante la gran innnovación de la Edad Media, el aristotelismo. De 1245 a 1248 le encontramos en París, en la Universidad, como «magister in sacra pagina»; antes regentó cátedras en Hildesheim, Friburgo, Ratisbona y Estrasburgo. Alberto se propuso hacer de nuevo inteligibles a los latinos todas las partes de la filosofía aristotélica, y esta vez la empresa fue coronada por el éxito. No sólo la lógica, también la física, la metafísica, la ética y la política fueron introducidas en el patrimonio común espiritual de la Escolástica, juntamente con las ideas de la ciencia arábigo-judía y de otras muchas fuentes diversas, particularmente neoplatónicas. Alberto conocido como «Doctor Universalis», por su espíritu enciclopédico, recibe a 60 años de su muerte el siguiente comentario de un cronista: «En este tiempo floreció el obispo Alberto, de la Orden de los dominicos, el más notable teólogo y más erudito de todos los maestros, y nadie, después de Salomón, se levantó tan grande ni parecido en toda la Filosofía..., pero como de nación era alemán, es aborrecido por muchos y su nombre despreciado, si bien se utilizan sus obras».

La otra figura insigne es Tomás de Aquino, nacido en 1224 de noble familia napolitana. A los 14 años lo encontramos en el estudio napolitano; a los 20 años entra en la orden dominica y un año después marcha a París para proseguir allí sus estudios con Alberto Magno; luego marcha a Colonia de 1248 a 1252 siguiendo el magisterio de Alberto. En 1256 se gradua simultáneamente con san Buenaventura de maestro en la Universidad de París. Tras una docencia de tres años volverá de nuevo a París como maestro de 1269 a 1272, siendo los años cumbre de su vida científica. Llenaron también este período molestas luchas con el clero secular, que lo mismo que en su primera estancia en París, también ahora se oponen a la actividad docente de los mendicantes.

En la llamada escuela franciscana posterior, al lado del aristotelismo de san Alberto y santo Tomás y sus respectivas escuelas, pervive también la antigua tradición agustiniana como una dirección propia y definida. Lo mismo que entonces son ahora sus representantes principales hombres de la orden franciscana.

El fundador de la llamada Escuela Franciscana Posterior es Duns Escoto (1266-1308), profesor en Oxford, Cambridge y París. En 1308 es llamado a Colonia, donde en el mismo año, cumplidos los 42 años de edad 
muere. Es sin género de duda uno de los primeros pensadores de la Escolástica. Es una mente crítica y se ha hecho acreedor justamente de su título de Doctor subtilis.

El dominico Eckhart (1260-1327) estudió en París y luego fue maestro en teología en la misma universidad.

El ocaso de los debates escolásticos, junto con la reacción franciscana representada por Duns Scoto y Guillermo Occam, irá acompañada, por la ocupación de cargos de todo tipo por franciscanos y dominicos ${ }^{9}$ en casi todas las universidades a lo largo del siglo XIV y posteriores. La lista sería interminable, pero después del cruel enfrentamiento entre el clero regular y el secular por la ocupación de las cátedras universitarias, la calma se instaló, aunque se abrían nuevos temas y campos de debate sobre el papel que las universidades representaban en las tesis conciliaristas, así como en todas las controversias de las herejías bajomedievales y reformas renacentistas.

\section{RÉSUMÉ}

Les Universités pendant le XIII ${ }^{\mathrm{e}}$ siècle subirent une profonde et longue crise de croissance et de consolidation. Un des principaux problèmes a été l'incorporation de professeurs provenant des Ordres Mendiants; ils se sont heurtés ouvertement aux intérêts de la Corporation des professeurs séculiers.

L'épreuve de force arriva au point culminant vers la moitié du siècle et termina avec le triomphe net des Mendiants, grâce à l'appui de la papauté et de la monarchie française.

\section{SUMMARY}

Throughout the thirteenth century, universities suffered a long and profound crisis of growth and consolidation. One of the principal problems involved the incorporation of professors from the Mendicant Orders and their headon clash with the guild interests of secular professors.

The conflict came to a head in the middle of the century and ended with a clear victory for the mendicants, thanks to the support of the papacy and the French monarchy.

${ }^{9}$ Sobre la importancia de los profesores y escritores dominicos, véase Laureano ROBLES, Escritores dominicos de la Corona de Aragón, s. XIII-XV. Salamanca, 1972. En donde queda patente el gran número de profesores universitarios de la citada orden y el gran papel intelectual que desempeñan en el ámbito de la Corona de Aragón. 